ORIGINAL ARTICLE

\title{
Impact of handgun types on gun assault outcomes: a comparison of gun assaults involving semiautomatic pistols and revolvers
}

\author{
D C Reedy, C S Koper
}

Injury Prevention 2003;9:151-155

\begin{abstract}
Objective: To examine whether gun assaults committed with semiautomatic pistols are more injurious and lethal than those committed with revolvers.

Setting: Jersey City, New Jersey from 1992 through 1996.

Methods: Using police records on fatal and non-fatal handgun assaults, $t$ tests and $\chi^{2}$ tests were employed to determine if attacks with pistols result in more shots fired than those with revolvers, leading to more gunshot victims and more severely wounded victims.

Results: More shots were fired in attacks with pistols (average $=3.2$ to 3.7 ) than in attacks with revolvers (average $=2.3$ to 2.6 ). Although pistol use was unrelated to the probability that an incident resulted in any injury or death, it was associated with a $15 \%$ increase in the number of wounded victims in those cases in which people were shot ( 1.15 per pistol case, 1.0 per revolver case), implying that the total number of gunshot victims may have been $9.4 \%$ lower had pistols not been used in any attacks. Pistol use was not related to the number of wounds per gunshot victim.

Conclusions: The findings provide limited evidence that recent growth in the production and use of pistols has contributed to higher levels of gunshot victimizations. However, available data did not permit an assessment of whether the associations between gun types and assault outcomes are mediated by characteristics of incidents and actors.
\end{abstract}

See end of article for authors' affiliations

Correspondence and reprint requests to: $\mathrm{Dr}$ Christopher S Koper, Jerry Lee Center of Criminology, University of Pennsylvania, 3814 Walnut Street,

Philadelphia, PA 19104,

USA;

ckoper@sas.upenn.edu
C minal misuse of firearms continues to be one of America's most serious crime and public health problems. Although rates of gun crime have fallen substantially in recent years, ${ }^{12}$ over 10000 persons were murdered with firearms in 2000 and another 49000 assault victims were treated in hospitals for non-fatal gunshot wounds..$^{13}$ The lifetime medical costs of gunshot injuries total approximately two billion dollars a year, with the majority of these costs stemming from criminal assaults. ${ }^{4}$

Handguns are heavily involved in firearm violence, accounting for $80 \%$ or more of guns used in urban crimes and homicides. ${ }^{5-7}$ During recent decades, there has been a shift away from production of revolvers to production of semiautomatic pistols in the civilian handgun market. Pistols grew from $28 \%$ of handgun production in 1973 to $46 \%$ by 1985 and to $80 \%$ by $1993 . .^{9}$ This trend is also apparent in criminal weaponry, as pistols have overtaken revolvers as the predominant type of handgun used in crime.

Semiautomatic pistols permit a somewhat more rapid rate of fire than do revolvers, and they often have larger ammunition capacities. The firing mechanism of a semiautomatic firearm loads a new round automatically after each shot. In most pistol models, the gun also recocks for firing automatically after each shot, thereby requiring less pressure on the trigger to fire after the first shot than is required with a revolver, which cocks for firing as the trigger is pulled. ${ }^{10}{ }^{11}$

Further, a pistol holds ammunition in a detachable magazine. Pistol magazines manufactured before September 1994 commonly hold five to 17 bullets, and magazines produced for some models take as many as 30 or more bullets. ${ }^{12}$ Production of pistols with magazines holding more than 10 rounds grew during the 1980s and early 1990s,, ${ }^{11}$ but was interrupted by the federal Violent Crime Control and Law Enforcement Act of 1994 (that is, the 1994 Crime Act), which now limits magazine capacity to 10 bullets. However, larger magazines manufactured before 13 September 1994 are still legal to possess and transfer. Revolvers, in contrast, hold ammunition in a revolving cylinder that typically has five to six bullets (and sometimes up to nine bullets). ${ }^{12}$

Pistols enable shooters to fire more shots more rapidly, potentially increasing the number of persons hit and wounds inflicted per shooting incident. Accordingly, it is possible that the increasing substitution of pistols for revolvers has increased deaths and injuries from gun violence. Such concerns have spurred legislation to restrict or deter the use of semiautomatic weaponry. In addition to limiting ammunition magazine capacity, for example, the federal 1994 Crime Act banned semiautomatic assault weapons (a group of semiautomatic, military-style pistols, rifles, and shotguns) and established penalty enhancements for violent and drug trafficking crimes committed with semiautomatics.

Yet evidence linking the spread of semiautomatic weaponry to higher levels of gun deaths and injuries is limited and equivocal. A few studies made indirect links between the growing use of semiautomatics and rising levels of gun homicide and injuries in some cities during the late 1980s and early 1990s. ${ }^{7}{ }^{13} 14$ However, other studies failed to demonstrate convincing links between city level trends in the use of semiautomatics and lethal gun violence. ${ }^{15}{ }^{16}$ National data also present mixed signs as to whether gun attacks have become more injurious and lethal as semiautomatics have become more prevalent. $^{21718}$

There is little direct empirical evidence on how semiautomatics affect attack outcomes. A few studies of firearm homicides suggest that pistol attacks involve more shots fired on average than attacks with revolvers and that victims killed with semiautomatics having large ammunition magazines (that is, those holding over 10 bullets) tend to receive more wounds than victims killed with other guns. ${ }^{79}$ However, there have been no studies comparing the injuriousness and lethality of attacks with pistols and revolvers. We address this gap using data on handgun homicides and non-fatal handgun 
assaults investigated by police in Jersey City, New Jersey during the early to mid-1990s.

\section{METHODS}

Jersey City, New Jersey is a city of approximately 230000 people. In 1990, its racial composition was $48 \%$ white, 30\% black, and $22 \%$ of other races. Approximately $11 \%$ of the city's residents were unemployed in 1990, and almost 19\% were living in poverty. ${ }^{20}$ Jersey City's violent crime rate in 1995 ranked 11 th among 136 cities with populations between 100000 and $250000 .^{21}$

The data for this study were collected from the homicide and aggravated assault files of the Jersey City Police Department. Comparisons of police and medical examiner records in urban jurisdictions show police records to be a highly accurate source of data for homicide cases. ${ }^{22-24}$ Police records are the single most comprehensive source for city level estimates of non-fatal, assaultive gunshot injuries in places (like Jersey City) that do not have firearm injury surveillance systems that combine police and medical data. ${ }^{23}{ }^{25}$ Moreover, police records are the only data source that can provide city level estimates of gun assaults not resulting in injury, thereby permitting examination of shots fired and hit rates for all gunfire incidents. However, the most minor types of gun assaults (for example, threats without gunfire, assaults resulting in minor or no wounds) tend to be under-represented even in police data. ${ }^{26}$ We assume that this bias works comparably for cases involving pistols and revolvers.

Jersey City police investigated 592 homicides and aggravated assaults involving handguns between January 1992 and November 1996. By law, aggravated assaults include cases in which offenders threatened victims with firearms, as well as cases in which offenders shot or attempted to shoot victims. From the case files, project staff recorded information on shots fired, the number of wounded victims, the number of wounds suffered by each victim, and the type(s) of firearm used in the attack as described by police and/or witnesses.

We estimated shots fired based on reported gunshot injuries, physical evidence (for example, shell casings found at the scene), and the accounts of witnesses and actors. If there was conflicting evidence about the number of shots, we established minimum and maximum ranges. If, for example, police found three shell casings at the scene but witnesses reported four shots, then we coded three as the minimum number of shots fired and four as the maximum number of shots fired. For many cases, the shots fired estimate represents a lower bound. To illustrate, if a case had one victim with one gunshot wound and no additional information on shots fired, then we set shots fired equal to one.

Our analysis focuses upon 239 incidents involving pistols and 104 incidents involving revolvers. We excluded 238 incidents from analysis because the type of handgun was not clearly identified in the police report. The analyzed and excluded cases had comparable outcomes: $38.0 \%$ of the excluded cases and $34.9 \%$ of the analyzed cases resulted in some form of gunshot injury, while $7.3 \%$ of the excluded cases and $8.0 \%$ of the analyzed cases resulted in deaths. These differences were statistically insignificant $\left(\chi^{2}\right.$ p level $\left.>0.05\right)$. In addition, we excluded 11 cases involving multiple handguns because we could not determine which gun(s) was used in the shooting.

Although reporting officers and witnesses were able to identify the type of firearm (that is, pistol or revolver) used in the analyzed cases, the precise make and model of the handgun was not identified in most of these reports, often because police did not recover the gun used in the crime. Lack of specific gun model information precluded precise measurement of ammunition capacity for all but a very small number of gunfire incidents.
Following an approach similar to that used by Kleck in his national analysis of gun and non-gun assaults, ${ }^{26}$ we contrast pistol and revolver cases on a number of dichotomous outcome measures (that is, occurrence of gunfire, occurrence of gunshot injuries or deaths) and continuous outcome measures (that is, number of shots fired, number of wounded victims, number of wounds per gunshot victim) reflecting different stages of gun assaults. In so doing, we test whether gun attacks with pistols result in more shots fired than those committed with revolvers, leading to more gunshot victims and/or more severely wounded gunshot victims.

Because the data were collected originally for a study of trends over time in wounds per gunshot victim, ${ }^{18} 19$ only limited information was recorded about the actors or circumstances beyond that noted above. While staff did collect information on a few variables like victim demographics (the victims were predominantly male and African-American) and the number of perpetrators, they did not record information on other potentially important variables, such as offender characteristics or relationships among the actors, ${ }^{26}{ }^{27}$ in a systematic manner, if at all, because such information was outside the scope of the original study and was not always clear from the reports. And since the data were extracted from the homicide and aggravated assault files, there were relatively few known robberies or sexual assaults among the cases (which would have generally appeared in separate case files), resulting in a more homogeneous sample of assaultive incidents. For these reasons, and because no prior study has examined the differential lethality and injuriousness of assaults involving pistols and revolvers, we chose to conduct bivariate analyses. We present $\chi^{2}$ tests of association for dichotomous measures and $t$ tests of group means for continuous measures, using a probability level of 0.05 to judge the statistical significance of results.

\section{RESULTS}

By definition, all cases in the study involved threats with a firearm. Hence, we begin our analysis by looking at whether offenders fired at their victims, which we define as an attack. (Unless stated otherwise, our unit of analysis is the incident rather than the victim since some incidents involved multiple victims.) As shown at the bottom of figs 1 and 2, assailants using pistols attacked victims in virtually the same proportion of cases as assailants using revolvers $(69.0 \%$ and $68.3 \%$, respectively). This implies that the type of gun used was not correlated with characteristics of actors or circumstances that might affect the probability of gunfire. In particular, it suggests that offenders using pistols were no more or less likely to attempt to injure or kill their victims than were offenders using revolvers.

Given that the gun was fired, the average number of shots in pistol cases ranged from 3.23 to 3.68 , based on minimum and maximum estimates (table 1). In contrast, the average number of shots in revolver cases ranged from 2.30 to 2.58 . Using both minimum and maximum shots fired estimates, pistol cases averaged about one more shot than did revolver cases, and this difference was statistically significant in both sets of comparisons.

Further inspection of table 1 shows that about two thirds (68.5\%) of pistol cases but only about half $(52.1 \%)$ of revolver cases involved multiple shots according to the minimum shots fired estimates. Using the maximum estimates, over three quarters (78.8\%) of pistol cases and about two thirds (66.2\%) of revolver cases involved multiple shots. Ten to thirteen percent of pistol cases involved more than six shots, the most common ammunition capacity for revolvers; in contrast, slightly less than $3 \%$ of revolver cases involved more than six shots. Finally, $3.6 \%$ to $4.2 \%$ of pistol cases involved more than 10 shots, the current limit on newly manufactured ammunition magazines. 


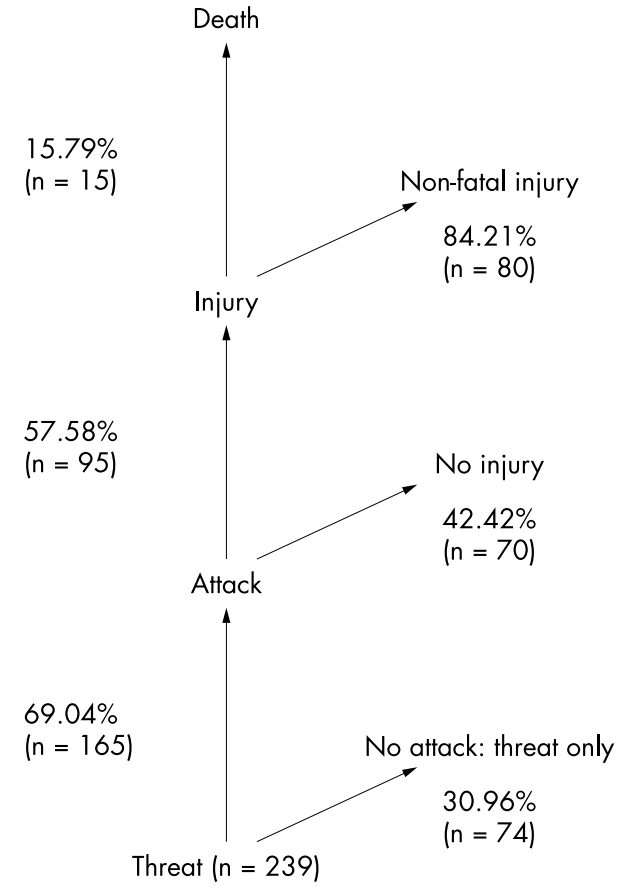

Figure 1 Outcomes of assault incidents involving semiautomatic pistols $(\mathrm{n}=239)$. Handgun type was not associated with attack outcomes $\left(\chi^{2}\right.$ p level $\left.>0.05\right)$.

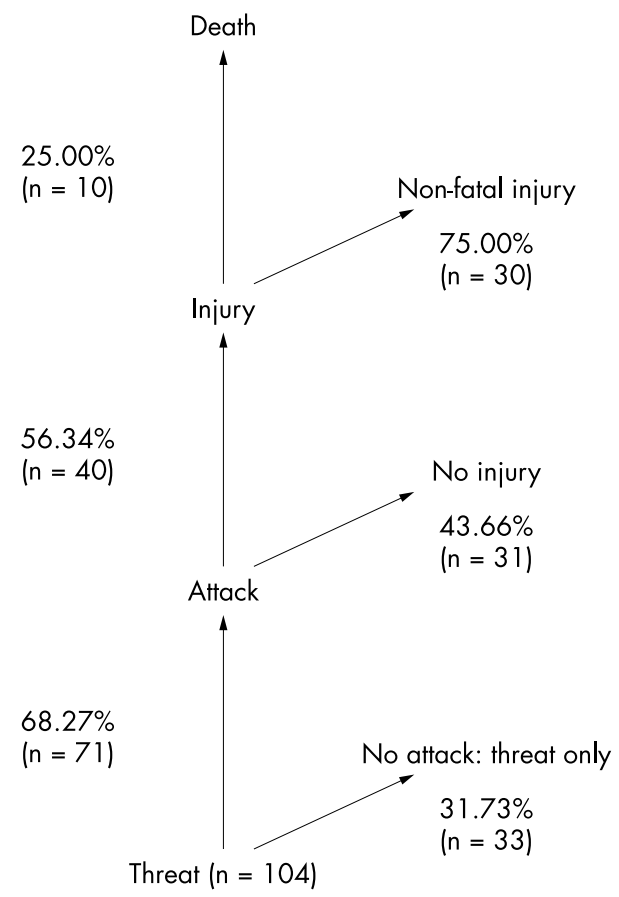

Figure 2 Outcomes of assault incidents involving revolvers ( $\mathrm{n}=$ $104)$. Handgun type was not associated with attack outcomes $\left(\chi^{2}\right.$ p level >0.05).

Although pistol cases involved higher numbers of shots, they were not significantly more likely to result in injuries (fatal or non-fatal) than were revolver cases. Attackers killed or injured victims in $57.6 \%$ of gunfire cases involving pistols and $56.3 \%$ of gunfire incidents involving revolvers (see figs 1 and 2).

However, pistol cases resulted in more wounded persons per incident than did revolver cases. Among those incidents resulting in gunshot victims, nearly $12 \%$ of the pistol incidents involved multiple victims in contrast to none of the revolver incidents. As shown in table 2 (left panel), the average number of victims was 1.15 in pistol incidents and 1.0 in revolver incidents. Though statistically significant, we should treat this finding cautiously because there was no variation in the number of wounded victims in the revolver cases (hence, the standard deviation was zero for revolver cases). Nonetheless, it appears that injurious attacks with pistols produced $15 \%$ more gunshot victims than did those with revolvers.

Extrapolating from this, there were 95 pistol incidents in which one or more persons were shot, producing a total of 109 victims wounded or killed (table 2). Yet our analysis suggests that only 95 persons would have been wounded in those 95 incidents if the offenders had used revolvers rather than pistols. This reduction of 14 gunshot victims would have reduced the overall number of gunshot victims by $9.4 \%$ $(14 /(109+40) \times 100)$.

Finally, figs 1 and 2 show that gunshot injury incidents involving pistols were less likely to produce a death than were those involving revolvers ( $15.8 \%$ to $25.0 \%$ ). A number of factors such as gun caliber, wound location, and the physical condition of the victim influence whether a gunshot victim dies. The higher fatality rate among revolver gunshot victims appears to have been linked, at least in part, to factors like wound location and age (analyses not shown). For example, $42.0 \%$ of the wounds sustained by revolver victims were wounds to the head, chest or abdomen, in contrast to only $25.2 \%$ of those sustained by pistol victims (wound location was known for $83.3 \%$ of the wounds inflicted with revolvers and $87.7 \%$ of those inflicted with pistols). Also, $14.3 \%$ of revolver gunshot victims but only $3.7 \%$ of pistol gunshot victims were over age 35 (age was recorded for $87.5 \%$ and $75.7 \%$ of revolver and pistol gunshot victims, respectively).

However, the key mechanism for a semiautomatic weaponry effect is the number of wounds-that is, does the higher number of shots fired in pistol cases increase the likelihood that gunshot victims will suffer multiple wounds, thereby making it more likely that the victims will die? Table 2 (right panel) contrasts the number of gunshot wounds sustained by victims in pistol and revolver cases. Although a higher percentage of pistol victims sustained multiple wounds ( $24.3 \%$ to $20 \%$ for pistol and revolver victims, respectively), the average number of wounds for pistol victims (1.44) was actually lower than that for revolver victims (1.50). However, neither of these differences was statistically significant. Therefore, we would not expect victims shot with pistols to die more frequently than victims shot with revolvers, holding gun caliber, wound location, the victim's physical condition, and other relevant factors constant.

\section{DISCUSSION}

This analysis of fatal and non-fatal gun attacks in Jersey City provides limited evidence that assaults committed with semiautomatic pistols produce more injured persons than assaults committed with revolvers. Gun attackers using pistols tend to fire more shots than attackers using revolvers. This shot differential does not appear to influence the probability that an incident will result in injury or death, nor the number of wounds sustained by gunshot victims. However, offenders using pistols do tend to wound more persons. Our analysis suggests that the overall number of wounded victims would have been reduced by $9.4 \%$ had revolvers been used in all of the attacks.

The results of this study should be qualified on a number of grounds. General limitations to the data were noted earlier. The shots fired variable was measured with less than optimal precision. Further, indicators of wounds per victim may be less accurate in police records than in medical records.

The effects of semiautomatics on gun attack outcomes could also be contingent on the particular models used; gun model identifications were usually missing in these data, thus 


\begin{tabular}{|c|c|c|c|c|}
\hline \multirow[b]{2}{*}{ Shots fired } & \multicolumn{2}{|c|}{ Minimum estimates } & \multicolumn{2}{|c|}{ Maximum estimates } \\
\hline & $\begin{array}{l}\text { Pistol incidents } \\
(n=165)\end{array}$ & $\begin{array}{l}\text { Revolver incidents } \\
(\mathrm{n}=71)\end{array}$ & $\begin{array}{l}\text { Pistol incidents } \\
(n=165)\end{array}$ & $\begin{array}{l}\text { Revolver incidents } \\
(\mathrm{n}=71)\end{array}$ \\
\hline 1 & $52(31.5)$ & $34(47.9)$ & 35 (21.2) & $24(33.8)$ \\
\hline 2 & 37 (22.4) & 13 (18.3) & 37 (22.4) & $20(28.2)$ \\
\hline 3 & 27 (16.4) & $9(12.7)$ & $33(20.0)$ & 9 (12.7) \\
\hline 4 & $13(7.9)$ & $5(7.0)$ & 19 (11.5) & $6(8.5)$ \\
\hline 5 & $13(7.9)$ & $6(8.5)$ & $11(6.7)$ & $8(11.3)$ \\
\hline 6 & $6(3.6)$ & $2(2.8)$ & $8(4.8)$ & $2(2.8)$ \\
\hline 7 & $4(2.4)$ & $2(2.8)$ & $3(1.8)$ & $1(1.4)$ \\
\hline 8 & $3(1.8)$ & 0 & $7(4.2)$ & 0 \\
\hline 9 & $2(1.2)$ & 0 & $3(1.8)$ & $1(1.4)$ \\
\hline 10 & $2(1.2)$ & 0 & $2(1.2)$ & 0 \\
\hline 11 & $1(0.6)$ & 0 & $2(1.2)$ & 0 \\
\hline 12 & $1(0.6)$ & 0 & $1(0.6)$ & 0 \\
\hline 13 & $1(0.6)$ & 0 & $1(0.6)$ & 0 \\
\hline 14 & 0 & 0 & 0 & 0 \\
\hline 15 & $1(0.6)$ & 0 & 0 & 0 \\
\hline 16 & $2(1.2)$ & 0 & $2(1.2)$ & 0 \\
\hline 17 & 0 & 0 & $1(0.6)$ & 0 \\
\hline Mean* & 3.23 & 2.3 & 3.68 & 2.58 \\
\hline
\end{tabular}

\begin{tabular}{|c|c|c|c|c|}
\hline \multirow[b]{2}{*}{ Victims/wounds } & \multicolumn{2}{|c|}{ Gunshot victims per incident } & \multicolumn{2}{|c|}{ Wounds per gunshot victim } \\
\hline & $\begin{array}{l}\text { Pistol cases } \\
\text { ( } n=95 \text { incidents) }\end{array}$ & $\begin{array}{l}\text { Revolver cases } \\
\text { ( } n=40 \text { incidents) }\end{array}$ & $\begin{array}{l}\text { Pistol cases* } \\
\text { ( } n=107 \text { victims) }\end{array}$ & $\begin{array}{l}\text { Revolver cases } \\
\text { ( } n=40 \text { victims) }\end{array}$ \\
\hline 1 & $84(88.4)$ & $40(100)$ & $81(75.7)$ & $32(80)$ \\
\hline 2 & $8(8.4)$ & & 13 (12.1) & $3(7.5)$ \\
\hline 3 & $3(3.2)$ & & $8(7.5)$ & $2(5.0)$ \\
\hline 4 & & & $3(2.8)$ & $1(2.5)$ \\
\hline 5 & & & $1(0.9)$ & $1(2.5)$ \\
\hline 6 & & & $1(0.9)$ & 0 \\
\hline 7 & & & 0 & $1(2.5)$ \\
\hline Meant & 1.15 & 1.0 & 1.44 & 1.5 \\
\hline
\end{tabular}

precluding examination of ammunition capacity or gun quality. Note that a number of the pistol models used most frequently in crime are inexpensive, lower quality guns (often referred to as Saturday Night Specials) that are prone to jamming and often don't have ammunition capacities larger than those of revolvers. ${ }^{28} 29$

In addition, multivariate studies controlling for characteristics of actors and situations might yield different results if those characteristics tend to be related to both weapon selection and attack outcomes. If, for instance, pistol shooters in this study tended to be younger and/or less skilled shooters than revolver shooters, this might explain why the former fired more often yet didn't injure or kill victims in a higher fraction of attacks and tended to hit victims in less vital areas of the body. Other potential confounders might include the nature of the circumstances (for example, whether the shooting was an execution-style shooting), the general health of the victim(s), the type of location (for example, indoor or outdoor location), the distance between the shooter and intended victim(s), and the presence of multiple persons who could have been shot intentionally or accidentally (as bystanders).

Taking the results at face value, nonetheless, this study has potential ramifications for national trends and policy, imply- ing that the spread of pistols during the last few decades may have contributed modestly to higher levels of assaultive gun injuries. Hence, policies to restrict or discourage the use of semiautomatic weapons or restrict ammunition magazine capacity might have the potential to reduce gunshot injuries.

We should be cautious about these inferences, however, because the analyses did not support all of our hypotheses about the effects of pistols. Further, achieving the moderate impacts suggested by this study would require complete elimination of the use of pistols in crime; to the extent that policy falls short of achieving this goal, the benefits may be substantially less and difficult to measure. Finally, these results may not generalize well to other places, although the differential in shots fired between pistol and revolver cases seems consistent with that found in other research. ${ }^{7}$

This study provides a first step in assessing differential levels of injury and death from attacks committed with different types of handguns, and it may spur replications to determine if these results can be generalized to other places and whether characteristics of the situations and actors mediate the relationships between weapon types and attack outcomes. Further research into the dynamics and outcomes of gun attacks can help to both clarify the consequences of changes in 


\section{Key points}

- During recent decades, there has been a shift in the civilian handgun market from production of revolvers to production of semiautomatic pistols, which tend to have larger ammunition capacities and a faster rate of fire.

- The consequences of this trend for public health are not clear, in part because no studies have directly compared the injuriousness and lethality of attacks with revolvers and pistols.

- This study of fatal and non-fatal gun attacks investigated by police in one city found that attacks with pistols tended to result in more shots fired and persons wounded than attacks with revolvers, implying that the number of gunshot victims would have been approximately $9 \%$ lower had pistols not been used in any of the attacks.

- The recent spread of semiautomatic pistols has likely contributed modestly to higher levels of assaultive gun injuries.

- Policies to restrict or discourage the use of semiautomatic weapons have the potential to reduce gunshot victimizations, but large reductions in the use of these weapons would be required to realize even modest declines in gunshot victimizations.

the civilian firearm arsenal and assess the potential impact of gun control measures designed to restrict the availability of particular types of firearms.

\section{ACKNOWLEDGEMENT}

Dr Koper conducted this research while working for the Urban Institute, Washington, DC.

This research was supported by grants 1995-IJ-CX-0111 and 1998IJ-CX-0039 from the National Institute of Justice (United States Department of Justice) to the Urban Institute. The Jerry Lee Center of Criminology, University of Pennsylvania and the Department of Criminology and Criminal Justice, University of Maryland provided additional support. The authors wish to thank a number of persons for assistance: Michael Buerger conducted on-site data collection; Jeffrey Roth provided advice on research design; Garen Wintemute, Charles Wellford, and Robert Brame offered helpful comments on earlier versions of this work; and Lois Mock served as grant monitor to the project. The views expressed are those of the authors and should not be attributed to the Urban Institute, the University of Maryland, the University of Pennsylvania, the United States Department of Justice, or any of the aforementioned individuals.

\section{Authors' affiliations}

D C Reedy, Department of Criminology and Criminal Justice, University of Maryland, College Park

C S Koper, Jerry Lee Center of Criminology, University of Pennsylvania, Philadelphia

\section{REFERENCES}

1 Rennison CM. Criminal victimization 2000: changes 1999-2000 with trends 1993-2000. NCJ-187007. Washington, DC: Bureau of Justice Statistics, US Department of Justice, 2001.
2 Gotsch KE, Annest JL, Mercy JA, et al. Surveillance for fatal and nonfatal firearm-related injuries-United States, 1993-1998. MMWR CDC Surveill Summ (April 13) 2001;50(SS-2): 1-34.

3 Simon TR, Saltzman LE, Swahn MH, et al. Nonfatal physical assault-related injuries treated in hospital emergency departmentsUnited States, 2000. MMWR Morb Mortal Wkly Rep 2002;51:460-3. 4 Cook PJ, Ludwig J. Gun violence: the real costs. New York: Oxford University Press, 2000.

5 Bureau of Alcohol, Tobacco, and Firearms. Crime gun trace analysis reports: the illegal youth firearms markets in 17 communities. Washington, DC: US Department of the Treasury, 1997.

6 Hargarten SW, Karlson TA, O'Brien M, et al. Characteristics of firearms involved in fatalities. JAMA 1996;275:42-5.

7 McGonigal MD, Cole J, Schwab CW, et al. Urban firearm deaths: a five-year perspective. J Trauma 1993;35:532-7.

8 Zawitz MW. Guns used in crime. NCJ-148201. Washington, DC: Bureau of Justice Statistics, US Department of Justice, 1995.

9 Bureau of Alcohol, Tobacco, and Firearms. Ready reference 1994. Washington, DC: US Department of the Treasury, 1994.

10 DiMaio JM. Gunshot wounds: practical aspects of firearms, ballistics, and forensic techniques. Boca Raton: CRC Press, 1993.

11 Wintemute GJ. The relationship between firearm design and handgun violence: handguns in the 1990s. JAMA 1996;275:1749-53.

12 Murtz HA ed. Guns illustrated 1994. Northbrook, IL: DBI Books, 1994

13 Webster DW, Champion HR, Gainer PS, et al. Epidemiologic changes in gunshot wounds in Washington, DC, 1983-1990. Arch Surg 1992; 127:694-8

14 Block CR, Block R. Street gang crime in Chicago. NCJ-144782. Washington, DC: National Institute of Justice, US Department of Justice, 1993.

15 Koper CS. Gun lethality and homicide: gun types used by criminals and the lethality of gun violence in Kansas City, Missouri, 1985-1993. College Park, MD: Department of Criminology and Criminal Justice, University of Maryland, 1995 (PhD dissertation).

16 Koper CS. Gun density versus gun type: did the availability of more guns or more lethal guns drive up the Dallas homicide rate, 1980-1992? Report to the National Institute of Justice, US Department of Justice. NCJ-187106. Washington, DC: Crime Control Institute, 1997.

17 Kleck G. Targeting guns: firearms and their control. Hawthorne, NY: Aldine de Gruyter, 1997

18 Koper CS, Roth JA. The impact of the 1994 federal assault weapon ban on gun violence outcomes: an assessment of multiple outcome measures and some lessons for policy evaluation. Journal of Quantitative Criminology 2001;17:33-74

19 Roth JA, Koper CS. Impact evaluation of the Public Safety and Recreational Firearms Use Protection Act of 1994. Washington, DC: Urban Institute, 1997.

20 Bureau of the Census. Washington, DC: US Department of Commerce, 1992.

21 Maguire K, Pastore AL, eds. Sourcebook of criminal justice statistics 1995. NCJ-158900. Washington, DC: Bureau of Justice Statistics, US Department of Justice, 1996.

22 Zahn MA, Riedel M. National versus local data sources in the study of homicide: do they agree? In: Waldo GP, ed. Measurement issues in criminal justice. Beverly Hills: Sage, 1983: 103-20.

23 Lee RK, Waxweiler RJ, Dobbins JG, et al. Incidence rates of firearm injuries in Galveston, Texas, 1979-1981. Am J Epidemiol 1991;134:511-21.

$24 \mathrm{Kim}$ AN, Trent RB. Firearm-related injury surveillance in California. Am J Prev Med 1998;15:31-7

25 Tuinen MV, Crosby A. Missouri firearm-related injury surveillance system. Am J Prev Med 1998;15:67-74.

26 Kleck G. Point blank: guns and violence in America. New York: Aldine de Gruyter, 1991.

27 Felson RB, Messner SF. To kill or not to kill? Lethal outcomes in injurious attacks. Criminology 1996;34:519-45.

28 Wintemute G. Ring of fire: the handgun makers of southern California. Davis, CA: Violence Prevention Research Program, University of California, 1994

29 Bureau of Alcohol, Tobacco, and Firearms. Crime gun trace analysis reports: the illegal youth firearms markets in 27 communities. Washington, DC: US Department of the Treasury, 1999. 